14.2

\title{
Предпосевная обработка озимой пшеницы поверхностным разрядом: устойчивость к низким температурам
}

\author{
() С.В. Гундарева, А.В. Лазукин, А.М. Никитин, Г.А. Романов \\ Национальный исследовательский университет „Московский энергетический институт“, \\ Москва, Россия \\ E-mail: gundareva-sv@rambler.ru
}

Поступило в Редакцию 9 апреля 2021 г.

В окончательной редакции 10 мая 2021г.

Принято к публикации 26 мая 2021г.

Проведена обработка семян мягкой озимой пшеницы длительного хранения продуктами низкотемпературной плазмы поверхностного разряда по непрямой схеме, т.е. в отсутствие контакта между слоем неподвижных семян и поверхностным разрядом, существующим в полосовой электродной системе с расстоянием между полосами $10 \mathrm{~mm}$. Семена выдерживались под действием разряда в течение $60 \mathrm{~s}$ в двух режимах питания электродов синусоидальным напряжением: $16 \mathrm{kHz} / 1.5 \mathrm{kV}$ и $4.4 \mathrm{kHz} / 2.4 \mathrm{kV}$. Оценивались морфофизиологические характеристики проростков на третьи и седьмые сутки, устойчивость закаленных проростков к низким температурам и зараженность семян. Установлено, что при условии высокой микобиотической нагрузки выполненная обработка не обеспечивает повышения качественных характеристик прорастания и устойчивости к низким температурам, а также не снижает зараженность семян.

Ключевые слова: поверхностный разряд, озимая пшеница, семена, проростки, устойчивость.

DOI: 10.21883/PJTF.2021.17.51384.18820

В настоящее время очередной виток в развитии получили методы предпосевной электрофизической подготовки, такие как воздействие на семена электрическим и магнитным полем, световым излучением, низкотемпературной плазмой. Это связано с тем, что существующие проблемы с качественными продуктами питания на отдельных территориях земного шара за последние 50 лет заметно обострились, и вопрос локальной продовольственной безопасности становится все более актуальным. Предполагается, что электрофизические методы обеспечат заметный вклад в решение этой проблемы и при этом сделают сельскохозяйственные технологии более „экологически дружественными“ за счет снижения расхода химических агентов, используемых для защиты и стимуляции культурных растений.

Среди методов электрофизической подготовки семян воздействие низкотемпературной плазмы (НТП) сочетает в себе наибольшее количество действующих факторов. В случае использования в качестве источника НТП электрического разряда атмосферного давления к таким факторам относятся действие излучения, тепла, химически активных частиц, электрического поля и объемного заряда. Различные схемы обработки посевного материала, пути взаимодействия между семенами и НТП, а также обстоятельства ответа семени на обработку можно найти, например, в обзо$\operatorname{pax}[1,2]$.

В качестве источников НТП при обработке семян распространение получили барьерные разряды атмосферного давления. В литературе можно найти довольно подробные обобщения по конструкциям и параметрам обработок семян в таких системах (см., например, [3]). При работе с семенами злаков повышения качественных характеристик прорастания можно ожидать при обработках высоковольтным барьерным разрядом за единицы минут. Однако необходимо учитывать тот факт, что НТП-обработка сортоспецифична.

Вопрос о повышении качественных характеристик прорастания и следующем за этим повышении урожайности после обработки семян НТП достаточно хорошо представлен в литературе (см., например, [4]). При этом данные об устойчивости к неблагоприятным факторам окружающей среды растений, полученных из обработанных НТП семян, пока носят фрагментарный характер, хотя в [2] сделаны предположения, что НТП-обработка повышает устойчивость ко всем видам стрессов, в том числе и к действию низких температур (ударных заморозков), что важно для регионов рискованного земледелия.

В работе [5] показано, что непрямая НТП-обработка поверхностным барьерным разрядом во влажном воздухе повышает устойчивость озимой ржи к действию низких температур.

В настоящей работе оцениваются качественные характеристики прорастания и устойчивость к низким температурам мягкой озимой пшеницы после обработки поверхностным разрядом семян длительного хранения.

В качестве объекта воздействия использованы семена мягкой озимой пшеницы сорта „Иркутская“ урожая 


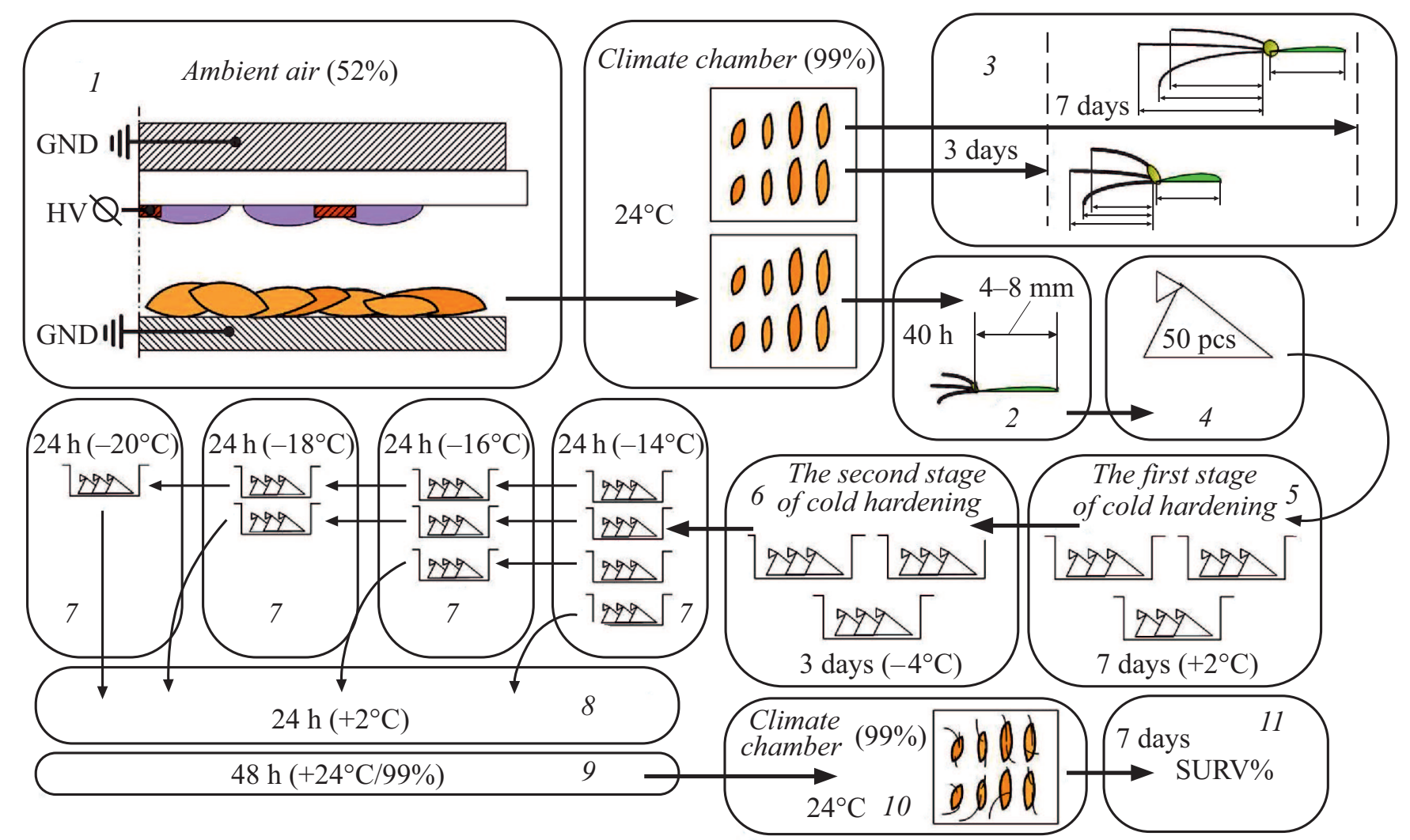

Рис. 1. Использованная в исследовании схема обращения с посевным материалом. В скобках указаны температура $\left({ }^{\circ} \mathrm{C}\right)$ и влажность (\%) воздуха на различных этапах. Этапы: 1 - обработка семян; 2 - отбор проростков после $40 \mathrm{~h} ; 3-$ анализ проростков после 3 и 7 дней; 4 - формирование проб по 50 штук; 5 - первый этап закалки (7 дней); 6 - второй этап закалки (3 дня); 7 - проморозка по $24 \mathrm{~h} ; 8$ - отмораживание $(24 \mathrm{~h}) ; 9$ - оттаивание $(48 \mathrm{~h}) ; 10$ - проращивание; 11 - подсчет доли выживших проростков.

2017 г. Семена получены из коллекций ЦКП „Биоресурсный центр“ Сибирского института физиологии и биохимии растений СО РАН (Иркутск). Все эксперименты выполнены с января по март 2021 г.

В работе [6] оценивался эффект от обработки поверхностным разрядом на более качественных (энергия прорастания около 95\%) семенах того же сорта мягкой озимой пшеницы. Семена урожая 2018 г. обрабатывались в 2019 г. Показано, что полосовая электродная система с расстоянием между параллельными полосами $10 \mathrm{~mm}$ обеспечивает увеличение морфологических характеристик проростков при напряжениях на электродах $2.4-2.7 \mathrm{kV}$ и экспозиции семян от 10 до $180 \mathrm{~s}$ (кроме отдельных случаев в этих диапазонах напряжений и экспозиций наблюдается практически равнозначный эффект).

Семена обрабатывались в полосовой электродной конфигурации поверхностного разряда, аналогичной использованной в $[5,6]$. Полосовые электроды шириной $1 \mathrm{~mm}$, выполненные из медной фольги, находились на расстоянии $10 \mathrm{~mm}$ друг от друга на поверхности диэлектрического барьера из оксида алюминия толщиной $1 \mathrm{~mm}$. Обратный электрод и электрод-плоскость заземлялись. Семена располагались на электроде-плоскости в один слой без перемещения в процессе выдержки. Расстояние между диэлектрическим барьером и электродом-плоскостью составляло $10 \mathrm{~mm}$. Высокое синусоидальное напряжение было приложено к полосовым электродам. Рассматривались два режима воздействия при выдержке семян под действием разряда длительностью $60 \mathrm{~s}: 16 \mathrm{kHz} / 1.5 \mathrm{kV}$ и $4.4 \mathrm{kHz} / 2.4 \mathrm{kV}$.

На рис. 1 показана использованная в работе схема обращения с семенами. После проведения обработки семян, разложенных в один слой на заземленном электроде (этап 1), семена с выдержкой не более часа закладывались на проращивание. Семена проращивались в термостате в темноте при $24 \pm 1^{\circ} \mathrm{C}$ и влажности $99 \%$ на двух слоях фильтровальной бумаги, увлажненной дистиллированной водой. Семена, приготовленные для оценки морфофизиологических характеристик, раскладывались на расстоянии около $5 \mathrm{~mm}$ друг от друга по три пробы на индивидуальный контейнер. Семена, приготовленные для оценки устойчивости к низким температурам, раскладывались ровным слоем по одной пробе на контейнер. Оценка относитель- 
Морфофизиологические характеристики проростков

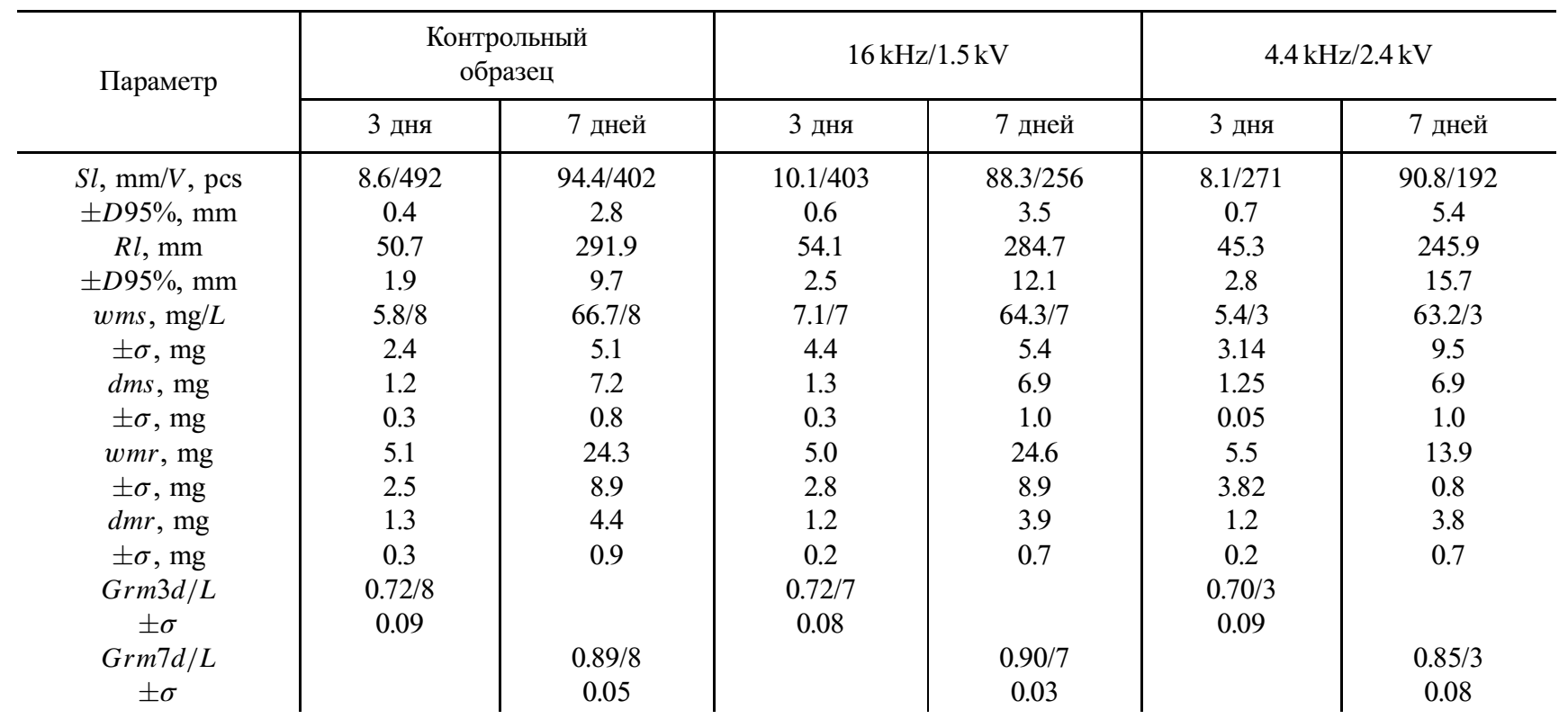

Пр и м е ч а и е. $S l$ - длина побега; $R l$ - суммарная длина индивидуальных корней; $w m s, d m s-$ сырая и сухая масса побега соответственно; $w m r$, $d m r$ - сырая и сухая масса корней соответственно; Grm $3 d-$ энергия прорастания; $G r m 7 d-$ всхожесть; $V-$ общее число растений, для которых оценивались средние значения $S l$ и $R l ; L-$ количество опытов; $D 95 \%$ - 95-процентный доверительный интервал; $\sigma$ - среднеквадратическое отклонение.

ной устойчивости проростков к низким температурам проводилась по методике [7], реализованной также в работе [5] для озимой ржи. Согласно методике [7], после $40 \mathrm{~h}$ проращивания проводился отбор проростков на длину побега 4-8 mm (этап 2). Остальные браковались в испытании на устойчивость. Семена, приготовленные для оценки морфофизиологических характеристик (этап 3), проращивались далее до трех и семи суток. Эти контейнеры увлажнялись и перемещались в термостате ежесуточно. Отобранные для оценки устойчивости проростки формировались в пробы по 50 штук (этап 4) и размещались в увлажненные марлевые мешочки. После прохождения двух этапов закаливания $(5,6)$ проводилась проморозка образцов (этап 7) с ежесуточным отбором. Отобранные образцы перемещались на оттаивание (этапы 8, 9). Затем семена раскладывались на проращивание (этап 10), после которого оценивалась доля выживших проростков (этап 11).

По проросткам, отложенным после обработки поверхностным разрядом, на третьи и седьмые сутки оценивались морфофизиологические характеристики: длина побега $(S l)$, суммарная длина индивидуальных корней $(R l)$, сырая и сухая массы побега $(w m s, d m s)$, сырая и сухая массы корней $(w m r, d m r)$, энергия прорастания $(G r m 3 d)$ и всхожесть $(G r m 7 d)$. Учитывались также общее число растений $(V)$, на которых оценивались средние значения $S l$ и $R l$, и количество опытов $(L)$, по которым оценивались массы и всхожести. Результаты измерения морфофизиологических характеристик для контрольного образ-

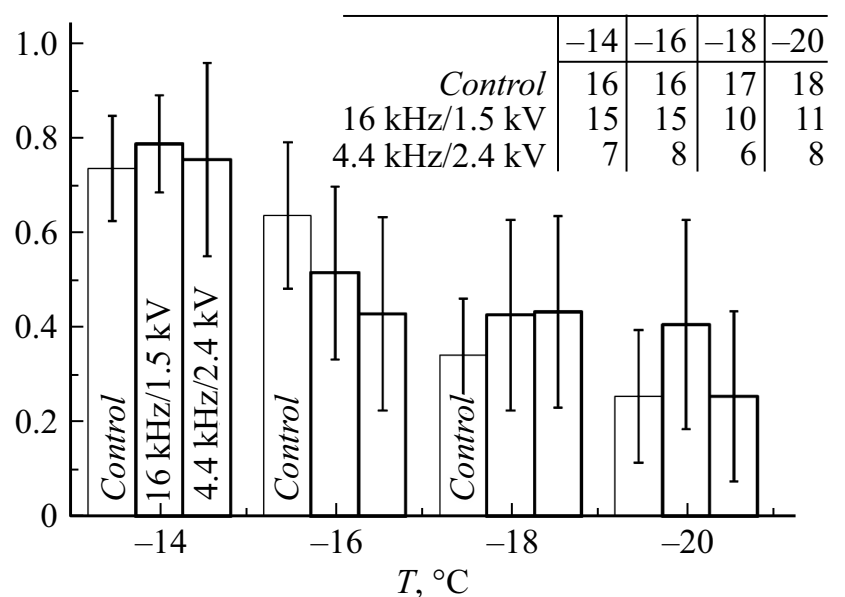

Рис. 2. Относительная морозоустойчивость проростков пшеницы. В таблице в верхней части рисунка указан размер выборки для каждого из вариантов с разбивкой по температурам.

ца (вариант без обработки) и семян после обработок поверхностным разрядом в течение $60 \mathrm{~s}$ в режимах $16 \mathrm{kHz} / 1.5 \mathrm{kV}$ и $4.4 \mathrm{kHz} / 2.4 \mathrm{kV}$ приведены в таблице.

Несмотря на длительное хранение, семена сохранили достаточно высокую энергию прорастания (72\%) и всхожесть (89\%). Обработки не оказывали заметного влияния на эти показатели. По остальным морфофизиологическим характеристикам на третьи сутки прорастания наблюдалось разнонаправленное влияние. Тен- 
денции к повышению длины побега, корневой системы и массы побегов (сырой и сухой) были обеспечены обработкой в режиме $16 \mathrm{kHz} / 1.5 \mathrm{kV}$. При обработке в режиме $4.4 \mathrm{kHz} / 2.4 \mathrm{kV}$ наблюдался обратный эффект по тем же показателям, кроме сухой массы корней. К седьмым суткам развития растений наблюдались тенденции к снижению практически всех морфофизиологических показателей в вариантах, подвергнутых обработке, относительно контрольного образца. Более явное снижение по длине и массе корневой системы было обнаружено при варианте обработки в режиме $4.4 \mathrm{kHz} / 2.4 \mathrm{kV}$.

Результаты оценки относительной морозоустойчивости проростков представлены на рис. 2. Различия в относительной морозоустойчивости не обнаружены. Однако в отдельных опытах наблюдалось значительное отрицательное влияние НТП-обработки, сопровождаемое интенсивным ростом фитопатогенов на заложенной пробе.

В том числе по этой причине в работе проводилось исследование зараженности семян на базе Лаборатории микологии и фитопатологии ВИЗР. Анализ зараженности зерна грибами выполнялся на питательной среде картофельно-сахарозного агара (КСА). При поверхностной стерилизации зерна предварительно замачивались в пакетах „BIOREBA“ в воде с добавлением ПАВ, далее промывались в проточной воде и стерилизовались с помощью $3 \%$ дезинфицирующего средства Ди-Хлор в течение 1-3 min. После использования стерилизующего средства зерна тщательно отмывались сначала водопроводной водой, а затем стерильной водой. В ламинарном боксе подсушенные, поверхностно стерилизованные зерна фламбировались в пламени горелки и раскладывались по десять штук на поверхность КСА, разлитого в чашки Петри. Предварительно в охлажденную до $55^{\circ} \mathrm{C}$ среду перед ее разливом добавлялись раствор смеси антибиотиков HyClone $^{\mathrm{TM}}$ в концентрации $1 \mathrm{ml} / 1$ для подавления роста бактерий и pactвop Triton X 100 в концентрации $0.004 \mu 1 / 1$ для снижения линейного роста мицелиальных грибов. Через десять суток инкубирования чашек Петри в темноте при $24^{\circ} \mathrm{C}$ в термостате проводился учет численности и видового разнообразия микромицетов. Зараженность зерна грибами (\%) рассчитывалась как отношение числа зерен, из которых были выделены грибы определенной таксономической группы, к общему числу анализируемых зерен. Общая сумма микромицетов может превышать значение числа анализируемых зерен, поскольку из одной зерновки может выделяться несколько микромицетов.

Анализ микобиоты зерна, не подвергнутого обработке, показал сравнительно высокую зараженность. Выделялись грибы рода Alternaria (зараженность зерна 80-89\%), Epicoccum (6-13\%), Trichothecium (7-14\%). Данные грибы относятся к непатогенным. Зараженность контрольного образца грибами рода Fusarium составила (2-6\%). Кроме токсинопродуцирующих грибов рода Fusarium на зерне также были отмечены токсинопродуцирующие грибы Penicillium (2-8\%) и Aspergillus (до 2\%). Другие представители микобиоты зерна встречались единично. Проведенные обработки не оказывали влияния на микобиоту. Вероятно, это связно с тем, что использованная НТП-обработка не относится к „прямым“, поскольку семена не контактируют с разрядом (в $[1,2]$ отмечается, что НТП является перспективной технологией для протравливания семян).

На основе проведенных исследований можно сделать следующие выводы. В результате НТП-обработки не удалось повысить качественные характеристики прорастания и устойчивость проростков из семян пшеницы длительного хранения при учете значительной степени их зараженности, в том числе в режимах, хорошо зарекомендовавших себя при исследованиях на более качественных семенах такого же сорта мягкой озимой пшеницы. Важно отметить, что, несмотря на то что НТП-обработка не повышает относительную морозоустойчивость, она не блокирует проведение закалки другим видом кратковременного стресса, в частности не препятствует закалке холодом.

Ряд исследований, в том числе проведенных нашим коллективом ранее, указывает на то, что НТП-обработка не обеспечивает надлежащую (ожидаемую) эффективность в условиях высокой зараженности зерна. Вероятно, отдельные факторы, сопряженные с НТП-воздействием, могут также положительно сказываться на развитии отдельных видов фитопатогенов, что полностью нейтрализует эффект от обработки.

\section{Благодарности}

Авторы выражают благодарность О.П. Гавриловой (Лаборатория микологии и фитопатологии им. А.А. Ячевского ФГБНУ ВИЗР).

\section{Финансирование работы}

Работа выполнена при финансовой поддержке Российского научного фонда (проект 18-76-10019).

\section{Конфликт интересов}

Авторы заявляют, что у них нет конфликта интересов.

\section{Список литературы}

[1] P. Starič, K. Vogel-Mikuš, M. Mozetič, I. Junkar, Plants, 9 (12), 1736 (2020). DOI: 10.3390/plants9121736

[2] L. Holubová, S. Kyzek, I. Duurovcová, J. Fabová, E. Horváthová, A. Ševčovičová, E. Gálová, Int. J. Mol. Sci., 21 (24), 9466 (2020). DOI: 10.3390/ijms21249466

[3] T.M.C. Nishime, N. Wannicke, S. Horn, K.-D. Weltmann, H. Brust, Appl. Sci., 10 (20), 7133 (2020). DOI: 10.3390/app10207133 
[4] M. Strejckova, A. Bohata, P. Olsan, Z. Havelka, P. Kriz, P. Beran, P. Bartos, V. Curn, P. Spatenka, J. Biomater, Tissue Eng., 8 (6), 829 (2018). DOI: 10.1166/jbt.2018.1819

[5] S.V. Gundareva, A.V. Lazukin, N.V. Dorofeev, A.G. Romanov, S.A. Krivov, J. Phys.: Conf. Ser., 1787, 012064 (2021). DOI: $10.1088 / 1742-6596 / 1787 / 1 / 012064$

[6] А.В. Лазукин, С.В. Гундарева, И.А. Моралев, С.А. Кривов, ЖТФ, 90 (10), 1621 (2020).

DOI: $10.21883 /$ JTF.2020.10.49790.398-19

[Пер. версия: 10.1134/S1063784220100114].

[7] И.И. Туманов, Методы определения морозостойкости растений (Наука, М., 1967), с. 77-83. 